University of the Pacific

Scholarly Commons

3-1-2001

\title{
Philosophical Counseling for Counselors
}

Lou Matz

University of the Pacific, Imatz@pacific.edu

Follow this and additional works at: https://scholarlycommons.pacific.edu/cop-facpres

Part of the Philosophy Commons

\section{Recommended Citation}

Matz, L. (2001). Philosophical Counseling for Counselors. Paper presented at American Philosophical Association Pacific Division Meeting.

https://scholarlycommons.pacific.edu/cop-facpres/987

This Conference Presentation is brought to you for free and open access by the All Faculty Scholarship at Scholarly Commons. It has been accepted for inclusion in College of the Pacific Faculty Presentations by an authorized administrator of Scholarly Commons. For more information, please contact mgibney@pacific.edu. 


\title{
Philosophical Counseling for Counselors
}

\author{
Lou Matz
}

Lou Matz is an Assistant Professor of Philosophy at the University of the Pacific, having previously taught at UC San Diego and Xavier University. He completed undergraduate degrees in psychology and philosophy at the University of Redlands and earned his Ph.D. at UC San Diego. He has published articles on Hegel, Kierkegaard, and Mill, and his research interests focus on ethics, the philosophy of religion, and the therapeutic value of philosophy.

\begin{abstract}
One promising form of philosophical practice is to conduct workshops on philosophical counseling for counselors. Since licensed professionals, such as Marriage and Family Counselors and Licensed Clinical Social Workers sometimes confront situations that raise philosophical issues and usually have a philosophical perspective that informs their practice, they could profit from a workshop on philosophical counseling; the workshop also qualifies for continuing education units (CEUs) that are typically required to renew their licenses. This paper describes the principal purposes of a workshop for counselors, the structure of two such workshops, and suggestions for improvement of future workshops.
\end{abstract}

One of the exciting aspects of the emerging field of philosophical practice is the opportunity to fashion different applications of philosophy outside of the academic setting. The completion of the American Philosophical Practitioners Association (APPA) certification workshop left me uncertain about what kind of philosophical practice I wanted to do. Having an undergraduate degree in psychology with an emphasis in counseling, I was initially attracted to the possibility of one-on-one client counseling. However, a conversation with my departmental colleague, Jim Heffernan, who also completed the APPA training, gave us an new direction. Jim's spouse is a Marriage and Family Therapist (MFT), and she and her therapist friends expressed skepticism about the legitimacy and merits of philosophical counseling. In a gesture of curiosity as well as self-interest, these therapists suggested that we put together a workshop on philosophical counseling so they could more reliably judge its merits as well as receive Continuing Education Units (CEUs) that are required to renew their licenses. We thereby created a workshop on Philosophical Counseling for Counselors and ran it for these therapists through our campus' Center for Professional and Continuing Education. A month later, we repeated the workshop, with some alterations, for the Human Services Agency in our county.

I believe that conducting workshops for counselors is perhaps the best option for 
philosophical practitioners who are naturally reticent to conduct one-on-one client counseling. First, effective client counseling requires real counseling skills, and these are neither gained through graduate degrees in philosophy nor naturally in abundance. Second, workshops are natural extensions of the teaching profession. Next, one does not have to worry at all about personal liability issues. Finally, there is a business niche for these workshops since certain health care professionals, such as MFTs and LCSWs, are required by the California Board of Behavioral Sciences (BBS) to complete CEUs in order to renew their licenses (eighteen hours for first renewal, and thirty-six hours for subsequent ones; one hour of instruction equals one CEU credit). After our first workshop on campus, my colleague and I obtained our own CE Provider License through the BBS, which is part of the California Department of Consumer Affairs, so that we could issue the CEUs ourselves.

The purpose of my paper is to discuss these workshops--their purpose, structure, reception, and possible improvements. The workshop on philosophical counseling for counselors serves two fundamental purposes: to make explicit the participants' own philosophical views on various issues that might inform their practice and to explore how philosophical methods could be applied to specific cases that they have encountered. In their evaluation of the workshop, participants appreciated other aspects of the experience that I had not anticipated, namely, the value of hearing the philosophical views of their colleagues, some of whom they had known for quite some time, and the opportunity to discuss the philosophical dimensions of their work among themselves, which they virtually never do.

\section{Structure of Workshop}

We divide the workshop into four sections: an introduction to philosophical counseling; the completion of a philosophical self-inventory; the discussion of the inventory and its relevance for their experience; and how philosophical methods might be more directly applied to their cases. 
In the introductory section, we explain the origin of modern philosophical counseling in ancient Greek and Roman societies, making reference to Socrates, the Hellenistic schools of Epicureanism, Stoicism, and Skepticism, and then the later Roman Stoics, such as Cicero, Seneca, and Epictetus. We then characterize the rise of contemporary philosophical practice, beginning in Germany in 1981 and made visible in America by the American Society for Philosophy, Counseling, and Psychotherapy. Finally, we describe the types of problems that philosophical practice is best fitted to serve by drawing on real examples from our years of teaching and my recent, though limited, one-on-one client counseling, such as those struggling with ethical issues (should one go away to graduate school or stay close by her father who is disabled? what does friendship demand? is homosexuality immoral? what is the extent of gratitude to others who have done good for you?) or with their religious upbringing (what are the personal repercussions of rejecting religious belief? does being moral require religious faith? why would God allow evil?).

In the second part of the workshop, participants complete a philosophical self-assessment on the following questions using a Likert scale:

1. Humans can know about reality through modalities other than their senses.

2. There is a God--an all-good, all-powerful creator and ruler of the universe.

3. Humans have free will and hence are morally responsible for what they do.

4. Humans are capable of doing things exclusively for the sake of others.

5. There are some moral truths so morality is not simply relative to one's society.

6. Any act is right if it has sufficiently good consequences

7. With reward and punishment in an afterlife, there is less incentive to be moral. These questions serve to make explicit some of the epistemological, religious, psychological, and ethical views that the participants hold. In the future, we will require that participants briefly explain the rationale for their views so that it can be more explicitly addressed in the subsequent discussion.

In the last two parts of the workshop, which form the bulk of it, we analyze each of the 
inventory questions from different philosophical perspectives. Short film clips are used to illustrate the philosophical problem and particular views on it (participants found the clips particularly illuminating). Along with the excursus of the different philosophical positions on the issues, we facilitated a discussion of the participants' own views, the reasoning for them, how these questions have been relevant in their practice, and how philosophical methods might be used as part of their intervention strategies. Since the discussion of the inventory questions is the core of the workshop, I want to briefly explain how we approached some of them and what connections the participants could make between them and their practice.

As revealed in their evaluation of the workshop, participants found the issue of ethical relativism (question five above) to be the most relevant for their practice. We first explained the possible grounds for a relativist position and then criticized the position with the arguments that James Rachels gives from his The Elements of Moral Philosophy, namely, that the cultural differences argument for relativism is a non-sequitur (differences of beliefs do not imply what is the case) and that relativism leads to various absurdities, such as the impossibility of moral progress and the incoherence of criticizing the ethical beliefs of other societies or the majority within one's own society. Moreover, sometimes what appears to be culturally different ethical values is really not since there is a shared, underlying value. Our presentation prompted two participants to share cases that involved the issue of relativism. One had a client who engaged in animal sacrifice for religious purposes but was charged with a crime. Another was confronted with a Polynesian client who claimed that incest was acceptable in his culture and felt that his criminalization in the United States was unjust. This second case left the practitioner morally confused and uncertain about what to say to the client. On the one hand, she wanted to be sensitive to cultural diversity, a commonplace mantra in our culture at large and within her agency; nonetheless, she firmly believed that incest was wrong, but could not explicitly produce the reasons that make incest wrong. After listening to the arguments against relativism, she found them persuasive and illuminating, but they did not directly address the specific issue of incest. Was this practice simply a rationalization for the sexual needs of the parent, as she 
believed? Was it possible that this is an instance where two cultures, at bottom, share a value, namely, that parents in both societies believe it important to show love to their children, but they disagree on how to do this? If so, this apparent relativism problem could be reducible to a factual question about whether incestuous relations harm children or not, and perhaps there are empirical studies which demonstrate this, e.g., the impairment of the child's capacity to form healthy sexual relationships in the future.

Regarding question six, we explained utilitarian and non-utilitarian (e.g., Kant) standards of ethics and applied them to specific moral issues that the participants might have encountered, such as homosexuality and suicide. We explained how these perspectives arrive at different conclusions on these two issues and what the weaknesses were with these two moral theories. During the discussion, one person realized, to her surprise, that she simultaneously held both of these moral views, which she recognized as inconsistent. She assumed a Kantian or natural law position regarding homosexuality (that is, that the natural "purpose" of sexuality is procreation) but relied on an utilitarian view for other moral questions, and she was not sure what to think in the end, although she saw the problems with appealing to nature as a standard of morality.

On the question of psychological egoism, we explained the various arguments against this position from Rachels' Elements of Moral Philosophy. One of the therapists raised an unanticipated but truly provocative point about narcissistic personalities. Even if psychological egoism is true, from a therapeutic point of view, there is still a critical distinction between normal and neurotic forms of self-love. Philosophers can forever debate the truth of egoism, but there is a practical reality that cannot await philosophical resolution, namely, that therapists must narcissistic personalities who cannot function.

Lastly, the issue of free will and determinism led to a lively discussion about how the capacity to choose can be impaired by social and psychological factors and hence free will is not an all or nothing reality. One experienced therapist explained how the fear of abandonment, effected by a breakdown of social relations during a child's development, has potentially devastating effects on the formation of self-esteem, and fragile self-esteem can restrict the kinds 
of choices the child makes as he or she develops. The other therapists chimed in with their examples to support this claim. This was an opportune moment for us to discuss the relevance of Peter Stawson's view in his paper "Freedom and Resentment" about the conditions which justify the modification of a person's reactive attitudes toward another and the adoption of a clinical attitude.

\section{Workshop Evaluation and Future Improvements}

I now conclude with the participants' reaction to the workshops and how future workshops might be improved. Clearly the best part of the workshop for the participants was that they found our discussion of the different philosophical views on the issues to be thought provoking and a stimulating challenge to their ways of thinking. They also felt better equipped to help clients reflect on their lives differently. In general, there was an unmistakable enthusiasm for philosophical discussion, which somewhat surprised us. People like to think about these philosophical issues, both for their own edification and for the benefits of their practice, but they have limited background and a lack of language to make their ideas more precise. One person perceptively remarked that there is an impoverishment of philosophical perspectives in our culture, i.e., that people have few resources to turn to, outside of traditional religion, in order to deal with philosophical or spiritual questions. Finally, as noted earlier, participants appreciated having time away from their daily duties to reflect on the philosophical aspects of their work and to learn about their colleagues' views about these issues.

In terms of future workshops, there are various ways to improve them. While there is some advantage to the more broad, overarching workshops that we conducted, I believe that therapists would be better served with more narrowly focussed workshops. There was simply not enough time to discuss the inventory questions in adequate depth or to consider their specific case studies. It would be better to conduct a few workshops for counselors, e.g., one devoted exclusively to ethics, another to religious and spiritual questions, etc. Another improvement 
related to conducting less general workshops is to add other relevant inventory questions, such as 'how much of one's life should be devoted to the happiness of others?'--relevant for cases in which women's assumptions about the scope of their moral obligations to others has harmed them--or 'are paternalistic laws and policies justifiable?' Such additional questions can be gathered through the workshop evaluation by asking participants to suggest other relevant issues.

Finally, the most pressing, and difficult, improvement is to develop how philosophical methods can be more directly applied to specific cases. A first step is to solicit from the participants in advance brief but detailed descriptions of their own cases that they would like to analyze during the workshop. The advantage for those conducting the workshop would be to have time to think through how philosophical methodologies might be brought to bear on these cases. In some cases, there might be clear solutions; in other cases, philosophical tools might help to produce unforeseen questions or issues without necessarily solving anything but that might nevertheless enrich the intervention.

I presented a shortened version of this paper at the American Philosophical Association Pacific Division Meeting on March 29, 2001 in San Francisco. 